\title{
Urgent surgery for COVID-19-positive pediatric patient
}

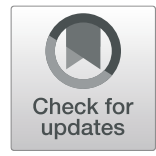

Franchesca Rivera-Calonje, Shiu-Yi Emily Chen, Carl Lo, Sang Le and Makoto Nagoshi* (D)

\begin{abstract}
Background: We present a case of COVID-19-positive pediatric patient for urgent urological surgery by spinal anesthesia to avoid aerosolizing procedure.

Case presentation: A 12-year-old, COVID-19-positive boy presented for urgent wound incision and drainage at the circumcision site. Our anesthetic plan consisted of spinal anesthesia with sedation. He was transported from the COVID-19 isolation floor to the negative pressure operating room. He was placed in lateral decubitus position and oxygen was delivered through facemask. Under sedation, spinal anesthesia was achieved at first attempt. The patient maintained spontaneous ventilation without airway intervention. Patient was recovered in the operation room then transported back to the floor.
\end{abstract}

Conclusion: Spinal anesthesia is a safe alternative to general endotracheal anesthesia for many pediatric urology procedures. Effective team communication and preparation are keys when caring COVID-19-positive patient in perioperative setting to avoid minimize the risk to healthcare providers.

Keywords: COVID-19, Pediatric anesthesia, Spinal anesthesia, Airway management, Perioperative management

\section{Introduction}

COVID-19 is highly infective and can spread through contact as well as respiratory and airborne transmission. Airborne transmission via aerosolizing procedures can infect individuals more than $6 \mathrm{ft}$. away [1]. During the Coronavirus Disease 2019 (COVID-19) pandemic, providers have found ways to limit viral transmission without compromising patient care.

Minimizing the risk of transmission is vital to safeguard the well-being of all Health Care Professionals (HCP) battling the COVID-19 global pandemic. The capacity for human-to-human transmission of COVID19 continues to pose a high-risk to all HCP in the perioperative setting [2]. When caring for a patient with COVID-19, the Anesthesia Patient Safety Foundation (APSF) recommends that prior to exposure to aerosolizing procedures $\mathrm{HCP}$ should protect themselves by

\footnotetext{
* Correspondence: mnagoshi@chla.usc.edu

Department of Anesthesiology and Critical Care Medicine, Children's Hospital Los Angeles, University of Southern California, 4650 Sunset Blvd, Los Angeles, CA 90027, USA
}

\section{Springer Open}

() The Author(s). 2021 Open Access This article is licensed under a Creative Commons Attribution 4.0 International License, which permits use, sharing, adaptation, distribution and reproduction in any medium or format, as long as you give appropriate credit to the original author(s) and the source, provide a link to the Creative Commons licence, and indicate if changes were made. The images or other third party material in this article are included in the article's Creative Commons licence, unless indicated otherwise in a credit line to the material. If material is not included in the article's Creative Commons licence and your intended use is not permitted by statutory regulation or exceeds the permitted use, you will need to obtain permission directly from the copyright holder. To view a copy of this licence, visit http://creativecommons.org/licenses/by/4.0/. (PPE) [3].

Spinal anesthesia achieves both surgical anesthesia and analgesia without airway intervention and can be performed safely and effectively, while minimizing aerosolization [4]. Spinal anesthesia in pediatric patients has, historically, been unpopular among both anesthesiologists and surgeons. Nonetheless, it has been proven effective in lower abdominal, urologic, and lower extremity procedures. Studies have indicated that spinal anesthesia is a suitable alternative to general anesthesia in neonates, young infants, and small adult patients undergoing minor surgery [5].

In a survey conducted by The Society for Pediatric Urology and European Society of Pediatric Urology, it was found that reluctance to accept spinal anesthesia for routine pediatric urologic procedures is multifactorial [6]. The belief that spinal anesthesia is technically challenging, and thereby increases preoperative time, may contribute to surgeon hesitation in incorporating this procedure. To the contrary, Nationwide Children's 
Hospital demonstrated that a dedicated team could induce spinal anesthesia in an average of four minutes [7].

The COVID-19 pandemic has led to questions about how to best care for COVID-19 patients perioperatively [8]. Currently, there are no guidelines extant in the literature for the anesthetic management of children with COVID-19.

As such, we present the case of a COVID-19-positive pediatric patient who successfully underwent urgent urological procedure with spinal anesthesia. This offers the first documented report of the use of regional anesthesia as primary anesthetic modality in a COVID19-positive pediatric patient.

\section{Case presentation}

A 12-year-old Latino male (BMI 25) presented 12 days post-circumcision for urgent revision surgery. The patient had no past medical history, no respiratory symptoms, and tested negative for COVID-19 at the time of his initial surgery. At his follow-up appointment, the pediatric urologist determined he required revision to avoid poor cosmetic outcome. He was subsequently brought to the hospital for incision and drainage of post-operative hematoma.

\section{Clinical findings}

On exam, the child was in clear discomfort and had a large hematoma completely surrounding the penile shaft. In adherence to Children's Hospital Los Angeles (CHLA) guidelines, the patient underwent nasopharyngeal COVID-19 swab testing prior to proceeding to the operating room (OR). His test returned positive for severe acute respiratory syndrome coronavirus (SARS$\mathrm{CoV})$. Per institutional policy, though he was asymptomatic, the patient was presumed to be carrying the virus and be high risk for disease transmission. Shortly after his positive result, we learned that the child's mother also had been infected with COVID-19 and was recuperating at home.

\section{Timeline}

After a risk-benefit discussion with the surgeon, spinal anesthesia with monitored anesthesia care (MAC) was recommended for this urgent procedure with the objective of avoiding instrumentation of the airway and minimizing the risk of airborne viral transmission. A plan was formulated together with nursing to ensure appropriate and effective communication throughout the case.

Once in proper PPE, the anesthesia and nursing teams transported the patient from the COVID-19 isolation floor to the negative pressure OR. He was transported in a wheelchair, donned in a face mask and isolation gown. At the end of the procedure, the recovery room nurse and OR staff transported the patient from the negative pressure OR, back to the COVID-19 isolation floor without complication.

\section{Diagnostic assessment}

The urgency of this case was discussed with the surgical team and it was concluded that postponing surgery because of his COVID-positive status was unacceptable due to his increased risk for long-term sequalae with his complication. A plan was made to mitigate risk to $\mathrm{HCP}$ using the following goals: (1) avoid airway instrumentation, (2) minimize airway manipulation, and (3) reduce overall risk of viral airborne transmission. As a successful spinal anesthetic does not require airway instrumentation or general anesthesia, it was especially suited to this urgent procedure [9]. The plan for spinal anesthesia was discussed with the child's parents in detail. The pediatric urologist lent support in educating the parents on the benefits of spinal anesthesia for this case. The parents later reported the surgeon's involvement helped make them comfortable with spinal anesthesia for their son.

\section{Therapeutic intervention}

Premedication was not provided until arrival in the OR to avoid potential sedation and respiratory depression that could necessitate airway intervention during transport. Standard anesthesia monitors were placed prior to administration of premedication. Spontaneous ventilation was confirmed with capnography and end-tidal $\mathrm{CO}^{2}$ monitoring. Sedation for spinal placement was achieved with propofol infusion at $35 \mathrm{mcg} / \mathrm{kg} / \mathrm{min}$ and incremental doses of ketamine $(24 \mathrm{mg})$ and dexmedetomidine $(16 \mathrm{mcg})$.The patient's back was prepped and draped in the usual sterile fashion at the level of the L3/L4 interspace. Lidocaine $1 \%(2 \mathrm{~mL})$ was used to provide local anesthesia to the skin. A Gertie-MarxTM 25-gauge spinal needle was used to access the spinal canal with return of clear cerebrospinal fluid (CSF).

Spinal anesthesia was achieved on the first attempt within $5 \mathrm{~min}$. A total of $2 \mathrm{~mL}$, consisting of bupivacaine $0.75 \%$ with dextrose $5 \%(1.5 \mathrm{~mL})$ and fentanyl PF 25 $\mathrm{mcg}(0.5 \mathrm{~mL})$ was given. The pediatric urologist then proceeded with their portion of the procedure. Surgical anesthesia was tested prior to incision and no response to noxious stimuli was appreciated. Surgery proceeded for $45 \mathrm{~min}$ with the patient breathing spontaneously throughout. There were no anesthetic complications or need for airway manipulation. The child was able to move his feet prior to discharge from the OR.

\section{Follow-up and outcomes}

Adequate preparation and communication proved essential in caring for this patient with COVID-19 [10]. Careful planning, clear communication, and precise anesthetic 
execution are needed for success. In this case, all parties, including the patient, his parents, the pediatric urologist, and the nursing teams were pleased with the anesthetic care provided for this patient.

\section{Patient perspective}

Post-operation discussion with the parent and patient highlighted the importance of patient-doctor rapport. Both the parent and patient were aware of the perioperative plan which they said served as a form of anxiolysis and facilitated the child's cooperation. The family and patient were satisfied with the care provided and appreciated the Anesthesiologist's effort to evaluate and minimize the potential risk of this urgent case.

\section{Discussion}

This is the first documented use of spinal anesthesia as primary anesthetic modality in a pediatric patient with novel COVID-19. Spinal anesthesia achieves both surgical anesthesia and analgesia without airway intervention [11]. This report highlights the importance of effective communication during the COVID-19 pandemic. The anesthetic approach demonstrated in this case effectively balances the safety of both patient and HCP, reducing the risk of spreading COVID-19 while simultaneously providing high-quality patient care. Unnecessary exposure to HCP was minimized by maintaining pediatric surgery left much to be desired. Five articles discussed the clinical findings communication and preparation are key to success when caring for COVID-19-positive patients in the perioperative setting to minimize the risk of viral transmission in a literature search in Spring 2020 [12].

At this time, there is no consensus on anesthetic management of patients with COVID-19. A literature review of 690 articles in PubMed, using the keywords "COVID19 pediatric surgery" left much to be desired. Five articles discussed the clinical findings associated with COVID-19 infection in children and one article indicated that multisystem inflammatory syndrome, which is common in children with COVID-19, may have cardiac involvement $[13,14]$.

Advances in the realm of pediatric regional anesthesia continue to evolve with excellent safety profiles described in society guidelines [15]. New data on the safety and efficacy of anesthesia experiences similar phenomenon. Anesthesiologists should be encouraged regional/neuraxial anesthesia in children continues to emerge from all over the world, even in remote settings such as rural Madagascar [16]. As the field of acute pain management and regional anesthesia continues to grow, the field of pediatric regional anesthesia experiences similar phenomenon. Anesthesiologists should be encouraged to advocate and provide education to surgical colleagues as well as patients and their families about the safety and efficacy of regional and neuraxial anesthesia.

Spinal anesthesia is a safe alternative to general endotracheal anesthesia for many pediatric urology procedures [17]. Data from The Ohio State University found that although rare, complications from spinal anesthesia include high spinal level (3.8\%), limited analgesic time (2.7\%), bradycardia (1.6\%), oxygen desaturation $(0.6 \%)$, and LA toxicity $(0.5 \%)$. Extremely rare complications include infection and neurologic injury (not some practitioners in performing neuraxial techniques can lead to some hesitancy to permanent). None of these complications were seen in this case [18]. Comfort level of some practitioners in performing neuraxial techniques can lead to some hesitancy to incorporate them into practice. It is important to be aware of the distinctions between pediatric and adult populations when performing spinal anesthesia. Limited analgesia time is common in children and must be taken into consideration $[5,9]$.

\section{Conclusion}

While the management of pediatric patients with COVID-19 must be individualized, spinal anesthesia should be strongly considered as an alternative to general anesthesia for lower abdominal and lower extremity surgery in COVID-19-positive pediatric patients.

\section{Acknowledgements \\ Not applicable.}

\section{Authors' contributions}

Franchesca Rivera-Calonje, MD: conceptualization, methodology, data curation, writing original draft. Emily Chen, MD: conceptualization, methodology, writing — review and editing. Carl Lo, MD: methodology, writing —review and editing. Sang Le, MD: writing - review and editing. Makoto Nagoshi, MD: writing-review and editing. All authors read and approved the final manuscript.

Funding

No funding was received for this case report.

Availability of data and materials Not applicable.

\section{Declarations}

Ethics approval and consent to participate

Written informed consent was obtained from the legal guardian for publication of this case report. Per institutional IRB policy, this case was exempted from IRB approval.

Consent for publication

The authors obtained informed consent from legal guardian for publication of this case report.

Competing interests

The authors declare that they have no competing interests. 
Received: 6 February 2021 Revised: 11 July 2021

Accepted: 12 July 2021 Published online: 22 July 2021

\section{References}

1. Alene M, Yismaw L, Assemie MA, Ketema DB, Mengist B, Kassie B, et al. Magnitude of asymptomatic COVID-19 cases throughout the course of infection: a systematic review and meta-analysis. PLoS One. 2021;16(3): e0249090. https://doi.org/10.1371/journal.pone.0249090.

2. Sanche S, Lin Y, Xu C, Romero-Severson E, Hengartner N, Ke R. High contagiousness and rapid spread of severe acute respiratory syndrome coronavirus 2. Emerg Infect Dis. 2020;26(7):1470-7. https://doi.org/10.3201/ eid2607.200282

3. Phan LT, Nguyen TV, Luong QC, Nguyen TV, Nguyen HT, le HQ, et al. Importation and human-to-human transmission of a novel coronavirus in Vietnam. N Engl J Med. 2020;382(9):872-4. https://doi.org/10.1056/NEJMc2001272.

4. Neal JM, Bernards CM, Hadzic A, Hebl JR, Hogan QH, Horlocker TT, et al. ASRA practice advisory on neurologic complications in regional anesthesia and pain medicine. Reg Anesth Pain Med. 2008;33(5):404-15. https://doi. org/10.1097/00115550-200809000-00003.

5. Williams RK, Adams DC, Aladjem EV, Kreutz JM, Sartorelli KH, Vane DW, et al. The safety and efficacy of spinal anesthesia for surgery in infants: the Vermont Infant Spinal Registry. Anesth Anal. 2006;102(1):67-71. https://doi. org/10.1213/01.ANE.0000159162.86033.21.

6. Rehfuss A, Bogaert G, Kogan B. Spinal anesthesia in children: most pediatric urologists are not on board. J Pediatr Urol. 2019;15:263. e261-5.

7. Walker BJ, Long JB, Sathyamoorthy M, Birstler J, Wolf C, Bosenberg AT, et al. Complications in pediatric regional anesthesia: an analysis of more than 100,000 blocks from the pediatric regional anesthesia network. Anesthesiology. 2018;129(4):721-32. https://doi.org/10.1097/ALN. 0000000000002372

8. Chen $\mathrm{X}$, et al. Perioperative management of patients infected with the novel coronavirus: recommendation from the Joint Task Force of the Chinese Society of Anesthesiology and the Chinese Association of Anesthesiologists. Anesthesiology. 2020;132:1307-16. https://doi.org/10.1 097/ALN.0000000000003301.

9. Gupta A, Saha U. Spinal anesthesia in children: a review. J Anaesthesiol Clin Pharmacol. 2014:30(1):10-8. https://doi.org/10.4103/0970-9185.125687.

10. Imran M, Yasmeen R. SARS-CoV2 Outbreak: Emergence, transmission and clinical features of human coronaviruses. J Ayub Med Coll Abbottabad. 2020;32(Suppl 1):S710-s713

11. Chun Y, Phillips M, Suresh S. Updates on neurologic complications in pediatric regional anesthesia. Minerva Anestesiol. 2021;87(6):695-703. https:// doi.org/10.23736/S0375-9393.20.14636-4. Epub 2020 Sep 22.

12. Chu DK, Akl EA, Duda S, Solo K, Yaacoub S, Schünemann HJ, et al. Physical distancing, face masks, and eye protection to prevent person-to-person transmission of SARS-CoV-2 and COVID-19: a systematic review and metaanalysis. Lancet. 2020;395(10242):1973-87. https://doi.org/10.1016/S0140-673 6(20)31142-9.

13. Castagnoli R, Votto M, Licari A, Brambilla I, Bruno R, Perlini S, et al. Severe acute respiratory syndrome coronavirus 2 (SARS- CoV-2) infection in children and adolescents: a systematic review. JAMA Pediatr. 2020;174(9): 882-9. https://doi.org/10.1001/jamapediatrics.2020.1467.

14. Valverde I, Singh Y, Sanchez-de-Toledo J, Theocharis P, Chikermane A, di Filippo S, et al. Acute cardiovascular manifestations in 286 children with multisystem inflammatory syndrome associated with COVID-19 infection in Europe. Circulation. 2021;143(1):21-32. https://doi.org/10.1161/circulationaha.120.050065.

15. Vargas A, Sawardekar A, Suresh S. Updates on pediatric regional anesthesia safety data. Curr Opin Anesthesiol. 2019;32(5):649-52. https://doi.org/10.1 097/ACO.0000000000000768.

16. Randriamizao $\mathrm{HM}$, et al. Use of spinal anaesthesia in neonates and infants in Antananarivo, Madagascar: a retrospective descriptive study. BMC Res Notes. 2020;13:1-6.

17. Practice advisory for the prevention, diagnosis, and management of infectious complications associated with neuraxial techniques: an updated report by the American society of anesthesiologists task force on infectious complications associated with neuraxial techniques and the American society of regional anesthesia and pain medicine. Anesthesiology. 2017;126: 585-601. https://doi.org/10.1097/ALN.0000000000001521

18. Brull R, McCartney C, Chan WW, Liguori GA, Hargett MJ, Xu D, et al. Disclosure of risks associated with regional anesthesia: a survey of academic regional anesthesiologists. Reg Anesth Pain Med. 2007;32(1):7-11. https:// doi.org/10.1016/j.rapm.2006.07.005

\section{Publisher's Note}

Springer Nature remains neutral with regard to jurisdictional claims in published maps and institutional affiliations.

\section{Submit your manuscript to a SpringerOpen ${ }^{\circ}$ journal and benefit from:}

- Convenient online submission

- Rigorous peer review

- Open access: articles freely available online

- High visibility within the field

- Retaining the copyright to your article

Submit your next manuscript at $\boldsymbol{\nabla}$ springeropen.com 